\author{
The real point of the awards is the opportunity to \\ demonstrate excellent ideas that push at the \\ boundaries of accepted behaviour in overall \\ dental care. .
}

\title{
OPINION
}

\section{Focussing on excellence}

Recently dentistry has been suffering at the hands of the UK national press again, which is such a common occurrence that I was not going to comment on it at all until I attended the Focus Awards on 23rd September where the contrast between the inferences in the newspapers and the reality of what some dental practices are doing was so immense I felt it was worthy of a mention.

As most UK dentists will know the media emphasis was on dentists 'extracting' £158 million pounds from the public purse by carrying out unnecessary treatment, namely 6-monthly regular check ups and scaling and polishing. This was just one aspect in the report from the Audit Commission, but it was seized upon with what seemed like glee by many of the nationals. While some of the press reports were reasonably fair others used emotive language to suggest that dentists were 'fleecing' their patients (Daily Express) and failed to recognise the illogicality of the argument that dentists were supposedly closing their lists to NHS patients while at the same time apparently over-treating them (also on the NHS). Perhaps the reporters thought that the few dentists seeing NHS patients had to be over-treating them to make the figures look right, as the evidence shows that the bulk of dentistry carried out at the moment is still under a GDS contract. Besides that, terms such as 'extortionate prices' do not help matters, especially when UK private fees are compared with the private fees in some other countries.

It seems strange that while the press distorts information to make a good story (as stated above) they always accept the fact that good news never sells. Perhaps they are right, which is why there were no reporters at the Focus Awards despite invitations being sent to all the media. But how did they know the Awards would feature such excellent examples of the complete reverse of the assumptions made about dentists taking advantage of patients, especially financially?

The Focus Awards is a joint Department of Health/BDA initiative recognising innovation in practices that 'focus' on patient care, and is now only in its second year (see report on page 478 of this issue for more information). As one of the judges I can honestly say that many of the entries demonstrated real innovation in their approach and delivery for the provision of total patient care, some of them surpassing many of the totally private practices around, yet to qualify the practices must have a patient base of at least $50 \%$ NHS patients, and most were greater than this.

The real point of the awards is the opportunity to demonstrate excellent ideas that push at the boundaries of accepted behaviour in overall dental care, especially the areas that matter the most to patients - the nonclinical aspects. Some examples from the four runnersup are: Lindley Dental Centre in Huddersfield provide a website where patients can book examination and emergency appointments; Strelley Dental Centre in Nottingham provides patients with 'digital diaries', a logbook of digital photographs of their treatment; Zetland House Clinic in Northallerton, North Yorkshire sends patients a map of parking areas prior to their visit; Clock House Dental Practice in York has a treatment advisor (not a dentist) who is available to discuss treatment plans with patients to ensure they understand what is being proposed and can make informed decisions; and the winner of the award, The Wessington Way Dental Practice in Sunderland has a patient forum to enable patients to participate in practice decisions, which has led (among other things) to patients themselves writing to other patients who fail to attend to state how unhappy patients are with regular DNAs.

of course the above examples are not the only innovations each practice has introduced, just some of the ones the judges felt were truly different. The $B D J$ will be publishing detailed descriptions of the winner and each finalist over the next few months to broadcast all their ideas. What impressed me though was the obvious enthusiasm of the patients, and one of the practices brought two of their patients to the ceremony.

It sounds a cliché, but listening to those patients tell me about the practice, seeing their faces and understanding how they felt about their care from the whole dental team encapsulated what real dental care as provided in the vast majority of dental practices is all about. What a shame that the journalists who are so ready to write about the supposed problems in dentistry did not bother to attend.

Mike Grace m.grace@bda-dentistry.org.uk 